\title{
APPLYING AN INDUSTRIAL DIVERSIFICATION DECISION MODEL TO SMALL REGIONS
}

\author{
Niles C. Schoening and Larry E. Sweeney*
}

\section{Introduction}

Diversification models based on the analysis of regional industrial portfolios were first developed in the 1970s and applied to the problem of minimizing employment instability in U.S. metropolitan areas (Conroy, 1974). Since then proponents of the portfolio approach have asserted that it can be a useful tool in devising both long and short term strategies to guide the growth of a region (Conroy, 1975; Barth, Kraft and Wiest, 1975; Cho and Schuermann, 1980; Spahr and Deckro, 1988). However, none of these authors has applied it to small regions such as a county located in a non-metropolitan area. The purpose of this paper is to assess the applicability of the industrial portfolio analysis approach in four non-metropolitan North Alabama counties. The authors contend that the lack of detailed time-series data seriously degrades the utility of this technique, not only in non-metropolitan regions but also in previously studied larger regions. When faced with these constraints, researchers in the past either have employed highly aggregated local data in their models or have substituted national data for missing local data. This leads to a misspecification of the variance-covariance matrix used to optimize the industrial mix of the region and consequently to erroneous policy recommendations.

\section{The Industrial Portfolio Model}

Under the portfolio analysis approach, the industrial mix of a region is viewed as analogous to a set of securities in the portfolio of an individual. Each industry in a region produces returns that consist of employment, wage and non-wage income. Such returns will vary over time, with both exogenously- and endogenously-produced changes affecting production, factor productivity, and the product mix of each industry. The returns to the physical resources of a region that are invested in a particular industry can be viewed as stochastic variables. If returns are stochastic, policy makers should consider not only the expected return

\footnotetext{
"Associate Professor of Economics, Department of Economics and Finance, College of Administrative Science, University of Alabama in Huntsville, Huntsville, Alabama and Assistant Professor of Finance, Department of Finance, College of Business, Ball State University, Muncie, Indiana.
}

on an investment but also the variance of the return when devising an economic development strategy. Couching the problem in terms of reducing fluctuations in aggregate returns to the region from its portfolio of industries makes employment stability a public policy goal and the issue of diversification focuses not only on the stability of each industry but also on the interdependence of all the industries in the region. An industry may be considered an appropriate or inappropriate policy choice depending on its relationship to all other industries in the region, i.e. an industry cannot be evaluated solely on its own stability or instability.

The variance of returns measures the risk involved in the stochastic process for individual industries. It is assumed that both investors and regions are averse to this risk. Following the definitions of risk and return relationships for portfolios of securities of Markowitz (1952), the portfolio variance $\sigma_{\mathrm{p}}$ for the industrial mix of a region is defined as:

$$
\sigma_{\mathrm{p}}=\sum_{\mathrm{i}} \sum_{\mathrm{j}} \mathrm{w}_{\mathrm{i}} \mathrm{w}_{\mathrm{j}} \sigma_{\mathrm{ij}}
$$

Where $w_{i}$ and $w_{j}$ are the proportions of regional employment associated with industries $\mathrm{i}$ and $\mathrm{j}$. Equation (1) can be disaggregated into its variance and covariance components thus:

$$
\sigma_{p}=\sum_{j} w_{j}^{2} \sigma_{j}^{2}+\sum_{i \neq j} \sum_{j \ngtr i} w_{i} w_{j} \sigma_{i j}
$$

From equation (2) it is clear how portfolio theory affects the choice of industries in developing a diversification strategy to reduce employment instability in a region. If regional policymakers have the choice of adding one of two industries, one of which has a large variance and the other a low variance, the better policy choice might be the high variance industry because total portfolio variance depends not only on industry variance but on the weighted sum of all covariances with other industries in the portfolio (the second term on the R.H.S.). If employment in the industry with the greater variance was uncorrelated with the employment in the other industries in the portfolio, or if it had large negative covariances with some or all of them, it might make a greater contribution to reducing total portfolio variance than the industry with the lower variance. 


\section{Model Applications}

This section focuses on applications of the portfolio analysis approach to the diversification problem. Conroy (1974) used national employment data for a 120 month period (January, 1958 through December, 1967) and applied them to local industrial structures in 52 U.S. metropolitan areas. This technique allowed him to generate policy choices for all extant three-digit SIC manufacturing groups located in each region. From these national data a unique variance-covariance matrix was estimated for the residuals of employment in each industry around a quadratic time trend, standardized about the mean of each time series. Each element of the matrix consisted of a covariance term of the following form:

$$
\hat{\partial}_{i j}=\left[\frac{1}{(n-2)}\right]\left[\frac{\left(m_{i t}-\hat{m}_{i t}\right)}{\bar{m}_{j}}\right]\left[\frac{\left(m_{j t}-\hat{m}_{j t}\right)}{\bar{m}}\right]
$$

Where $\hat{\mathrm{m}}_{\mathrm{it}}$ and $\hat{\mathrm{m}}_{\mathrm{jt}}$ denote observed national levels of manufacturing employment in industries $i$ and $j$ during month $t$ and $m_{\mathrm{it}}$ and $\mathrm{m}_{\mathrm{jt}}$ are predicted levels of employment given by the quadratic trend equation and $\overline{\mathrm{m}}_{i}$ and $\overline{\mathrm{m}}_{\mathrm{j}}$ are arithmetic means of the time series for industries $i$ and $j$. [This method of measuring covariances also was used by Jackson (1984), and suggested by Spahr and Deckro (1988).]

Conroy justified measuring the covariances from a time trend rather than from the mean because most manufacturing industries were experiencing steady increases in employment during the period he studied. Measuring covariances from a trend equation rather than from the mean, however, leads to over- or underestimates of the covariances and creates a problem of interpretation. This difficulty was addressed directly by Cho and Scheurmann (1980) and St. Louis (1980). Their models employed variance-covariance matrices based on the monthly percentage changes in industry employment, with a single covariance term in equation (2) taking the form:

$$
\begin{aligned}
& \quad \sigma_{i t}=\left[\frac{1}{(n-2)}\right]\left[g_{i t}-\hat{y}_{i}\right]\left[g_{j t}-\hat{y}_{j}\right] \\
& \text { Where } g_{i t}=\frac{m_{1 t+1}-m_{1 t}}{m_{i t}} \\
& \text { And } y_{i}=\frac{1}{N} \sum_{t=1}^{N} g_{i t}
\end{aligned}
$$

Except for that of Conroy, all the above mentioned models lack industry detail, and thus suffer from aggregation problems. The model of Cho and Scheurmann tests six manufacturing sectors and a total of only 13 sectors, that of
St. Louis evaluates just one manufacturing sector and a total of ten sectors. The model applied by Jackson has more detail (14 manufacturing sectors and a total of 21 sectors) but is still highly aggregated. All of these models were applied either to metropolitan areas or to other large geographic regions.

\section{Data Set for a Small Area}

Two methods have been employed in earlier studies to find an optimal portfolio of industries for a region. One is to devise a variance-covariance matrix based on an employment time series for a larger region or for the national economy. This preserves a high degree of detail because the mix of 3-digit SIC groups in the region is optimized. The second alternative is to create a matrix based exclusively on local data and come up with industrial sectors aggregated into 2-digit SIC manufacturing groups or even a single sector for manufacturing.

In this section, a third procedure for creating a manufacturing employment series that is based on local data and also provides a fairly high degree of industrial detail is presented. The major shortcoming of this approach is that it appears to be applicable only in a few nonmetropolitan counties. Tests also were made to determine whether this approach generated significantly different total portfolio variances than the other methods. A smallsample likelihood ratio test (Hoel, 1962) was used to test for the equality of the total portfolio variances found with the various methods. The first step in this process was to construct a benchmark matrix with enough detail to be relevant to policymakers and that was based entirely on local employment data. The data reported for 25 non-metropolitan Alabama counties in County Business Patterns (CBP) (USDC, 1966-85) - the only readily available small-area employment data that are sufficiently detailed to be useful in selecting industrial portfolios in non-metropolitan counties - were reviewed. It was decided to limit the analysis to manufacturing industries since these are fully covered in CBP. Data were collected for the years 1966 through 1985 and were adjusted because of changes in definitions of industrial classifications during the period. Because the CBP data are based on March figures for employment drawn from social security tax forms, the data may be seasonally biased and may result in under- or overestimates of the actual sizes of certain industrial sectors.

Because a three-digit manufacturing SIC code may contain only one or two plants in a particular county, employment data for that code may not be reported in CBP. Each of the 25 non-metropolitan counties in Alabama was evaluated as to the number of suppressed entries during the 20 year span. Four counties that had the highest percentage of reported entries were chosen. The four North Alabama 
counties selected, with their 1980 populations in parentheses, were: Cullman (61,642); Franklin (28,350); Marshall $(65,622)$; and Morgan $(90,211)$. Each of these counties experienced an increase in manufacturing employment between 1966 and 1985 with Marshall County growing at a five percent compound annual rate; Cullman, growing at 3.5 percent; Franklin, at 3.7 percent; and Morgan, at 1.4 percent. The smallest county, Franklin, had 13 three-digit manufacturing industries; Morgan, the largest county, had 30 three-digit industries.

Suppressed entries in CBP were estimated in several ways. If a number was reported at the two-digit but not at the three-digit level of disaggregation the two-digit entry was used in the employment time series for the county. An entry was estimated through interpolation or imputation if enough entries were reported elsewhere in the CBP tables to permit it. When these methods proved unworkable, CBP data were supplemented with information from state and local industrial directories and the Census of Manufacturers.

The characteristics of the entries for each of the four counties are summarized in Table 1. The total number of manufacturing jobs reported for each county in the 1985 CBP is shown in the first row of the table. The number of three-digit manufacturing industries located in the county at any time during the $1966-1985$ period, is listed in the second row. The total number of three- and two-digit industries represented in the county employment series is shown in row three. The total number of entries in the complete variance-covariance matrix for the county is found in row four.

During the twenty year period, industries started or ceased operations in each county, creating zero entries in each employment matrix. The zero entries were retained if they occurred in the middle of a time series for a particular industry (i.e., a plant opened up, shut down and then re-opened); they were eliminated if they ocurred at the beginning or end of the series (i.e., a new plant moved in and stayed open for the remainder of the period or a firm closed down permanently). The number of three-digit industries moving in or out of the county or opening up and closing down is shown in rows five and six of Table 1 . The number of non- zero entries reported in CBP in the twenty year period for each county is found in the seventh row and this number is shown as a percentage of the total number of entries for that county at the bottom of the table. The percentages range from a low of 56.8 percent in the employment series for Franklin County, to a high of 75.0 percent for Morgan County, the smallest and largest counties, respectively.

Total portfolio variance was calculated for each of the four counties using six different matrices: an employment matrix based on the local data, one based on state data, and one on U.S. data. Each of the matrices used industry weights that reflected employment in the county in 1985. A covariance term based on equation (2) was calculated from the mean of each standardized employment time series:

$$
\sigma_{i j}=\left[\frac{1}{(n-2)}\right]\left[\frac{m_{i t}}{\bar{m}_{i}}-1\right]\left[\frac{m_{j t}}{\bar{m}_{j}}-1\right]
$$

Following Conroy (1974) a time trend for each standardized time series also was calculated and covariances were measured from the estimated standardized employment values in each time period using equation (3).

Table 1

Characteristics of Local Employment Data Entries, Four Nonmetropolitan Alabama Counties

\begin{tabular}{|c|c|c|c|c|c|}
\hline & \multirow[t]{2}{*}{ Unit } & \multicolumn{4}{|c|}{ County } \\
\hline & & Cullman & Franklin & Marshall & Morgan \\
\hline Total Mfg. Employment 1985 & number & 5,335 & 3,261 & 10,161 & 12,189 \\
\hline 3-digit Mfg. Industries & & & & & \\
\hline Reported in CBP & number & 17 & 13 & 24 & 30 \\
\hline 3-digit and 2-digit Mfg. Industries & & & & & \\
\hline in Employment Series (n) & number & 15 & 11 & 20 & 27 \\
\hline Total Entries ( $\mathrm{n} \times 20)$ & $(\mathrm{n} \times 20)$ & 300 & 220 & 400 & 540 \\
\hline $\begin{array}{l}\text { 3-digit Mfg. Industries Moving } \\
\text { into County: 1966-1985 } \\
\text { 3-digit Mfg. Industries Leaving }\end{array}$ & number & 8 & 7 & 11 & 11 \\
\hline County: $1966-1985$ & number & 3 & 1 & 1 & 2 \\
\hline $\begin{array}{l}\text { Non-Zero Entries Reported } \\
\text { (Total Entries with reprted }\end{array}$ & number & 199 & 125 & 287 & 405 \\
\hline non-zero no.) & percent & (66.3) & $(56.8)$ & $(71.8)$ & $(75.0)$ \\
\hline
\end{tabular}


Table 2

Likelihood Ratio Tests of Differences Among Intracounty Measures of Industrial Portfolio Variances of Industrial Employment, Four Alabama Counties

\begin{tabular}{lcccc}
\hline & \multicolumn{3}{c}{ Level of Measurement of County Industrial Employment } \\
\cline { 2 - 5 } County & \multicolumn{2}{c}{ U.S. Minus County } & \multicolumn{2}{c}{ Alabama Minus County } \\
Mean & Trend & \multicolumn{2}{c}{ Mean } & Trend \\
\hline Cullman & $52.776^{\mathrm{a}}$ & $31.229^{\mathrm{a}}$ & $10.552^{\mathrm{a}}$ & $8.561^{\mathrm{a}}$ \\
Franklin & $47.039^{\mathrm{a}}$ & $36.188^{\mathrm{a}}$ & $21.625^{\mathrm{a}}$ & $15.998^{\mathrm{a}}$ \\
Marshall & $49.405^{\mathrm{a}}$ & $29.570^{\mathrm{a}}$ & $26.959^{\mathrm{a}}$ & $16.011^{\mathrm{a}}$ \\
Morgan & $4.821^{\mathrm{b}}$ & 1.329 & $8.072^{\mathrm{a}}$ & $4.958^{\mathrm{b}}$ \\
\hline
\end{tabular}

$\mathrm{a}=$ significant at the 0.01 level.

$\mathrm{b}=$ siginificant at the 0.05 level.

The portfolio variances for each matrix were compared to the variances calculated from local employment data in pair-wise fashion. The resulting chi square values for the small sample likelihood ratio tests are shown in Table 2. With only one exception, the portfolio variances measured from matrices constructed from U.S. and state employment data differed statistically from the variances from local data at the one percent or five percent level of confidence. These results were the same whether the covariances were calculated from a trend value or the mean. The only exception was found in Morgan County, the largest county, in comparing the locally derived matrix of trended employment data to a matrix using U.S. data.

These results indicate that despite all matrices for a particular county containing the same industries and having the same industry weights, there were enough differences in the cyclical behavior of employment to warrant the conclustion that the U.S., state, and locally-based matrices represent essentially different portfolios.

\section{Conclusion}

Serious data limitations make it difficult to apply portfolio analysis to the choice of an optimal industrial diversification strategy in non-metropolitan counties. The authors reviewed data for 25 such counties in Alabama and only four met the criterion of having sufficient data reported in CBP for inclusion in the study. Even so there were several suppressed entries in each of the counties analyzed. When faced with similar limitations other researchers have used either greatly aggregated local data or data from larger geographic areas such as the state or the U.S. The first option generates policy choices that are too generalized to provide much guidance to policy makers; the second option leads to optimizing a portfolio of industries that is significantly different from the local portfolio.
From this evidence it appears that the choice is limited to local employment data for constructing variance-covariance matrices for industrial portfolio analyses. Because of the lack of reliable local data the technique appears to be inappropriate for depicting policy options to guide local economic development efforts in most nonmetropolitan areas of the country.

\section{References}

Barth J., J. Kraft and P. Wiest, "A Portfolio Theoretic Approach to Industrial Diversification and Regional Employment." Joumal of Regional Science 15. (1975). 9-15.

Cho, D.W. and A. C. Schuermann. "A Decision Model for Regional Industrial Recruitment and Development." Regional Science and Urban Economics 10. (1980). 259-273.

Conroy, MichaelE. "The Concept and Measurement of Regional Industrial Diversification." Southern Economic Joumal 41. (1975). 492-505.

"Alternative Strategies for Regional Industrial Diversification." Journal of Regional Science 14:1. (1974). $31-46$.

Hoel, Paul G. Introduction to Mathematical Statistics. New York: John Wiley and Sons, Inc. (1962).

Jackson, Randall W. "An Evaluation of Alternative Measures of Regional Industrial Diversification.” Regional Studies 18. (1984). 103-112.

Markowitz, H. “Portfolio Selection." Journal of Finance (1952). 77-91.

St. Louis, Larry V. "A Measure of Regional Diversification and Efficiency." Annals of Regional Science 14. (1980). 21-30. Spahr, Ronald W. and Richard F. Deckro. "A Non-linear Goal Programming Approach to Modeling Intraregional Economic Development." REVIEW OF REGIONAL STUDIES 18:1. (1988). 10-18.

U.S. Department of Commerce. County Business Patterns. (1966-1985). 